REVIEW ARTICLE

\title{
Clinical Manifestations and Characterization of COVID-19 in Liver Transplant Recipients: A Systematic Review of Case Reports and Case Series
}

\author{
Pirouz Samidoust $^{*}$, Hamed Nikoupour ${ }^{2}$, Hossein Hemmati ${ }^{1}$, Aryan Samidoust ${ }^{1}$
}

OPEN ACCESS

Citation: Pirouz Samidoust, Hamed Nikoupour, Hossein Hemmati, Aryan Samidoust. Clinical Manifestations and Characterization of COVID-19 in Liver Transplant Recipients: A Systematic Review of Case Reports and Case Series. Ethiop J Health Sci. 2021;31 (2):429. doi: http://dx.doi.org/ 10.4314/ejhs.v31i2.26

Received: December 3, 2020

Accepted: December 6, 2020

Published: March 1, 2021

Copyright: (C) 2021 Samidoust P, et al. This is an open access article distributed under the terms of the Creative Commons Attribution License, which permits unrestricted use, distribution, and reproduction in any medium, provided the original author and source are credited.

Funding: Nil

Competing Interests: The authors declare that this manuscript was approved by all authors in its form and that no competing interest exists. Affiliation and Correspondence:

${ }^{1}$ Razi Clinical Research Development Unit, Razi Hospital, Guilan University of Medical Sciences, Rasht, Iran

${ }^{2}$ Shiraz Transplant Center, Abu Ali Sina Hospital, Shiraz University of Medical Sciences, Shiraz, Iran Email: samidoust99@gmail.com

\section{ABSTRACT}

BACKGROUND: This systematic review is conducted to explore available information on clinical presentations, laboratory finding and outcomes of SARS-COV-2 in liver transplant patients.

METHODS: We searched four databases for relevant terms related to COVID-19 and liver transplantation and collected both case reports and case series on liver transplantation published up to the end of September 2020.

RESULTS: After initial screening of irrelevant articles, 25 studies were included and analyzed in this review. Among the 59 patients included, $78.3 \%$ were over 50 years old, and $71.6 \%$ were males. The majority of patients (93.3\%) were hospitalized. The most common presenting symptoms were fever (72.9\%) followed by dyspnea and cough (54.2\%). The majority of patients revealed a high level of CRP (64.3\%). Moreover, high level ALT, AST and ALP were reported in $64.3,37.5,30.5$ and $22.2 \%$ of patients. $A$ total, 9(15.3\%), of cases died as a result of complications of COVID-19. Chest radiographs were reported in $72.9 \%(43 / 59)$ of cases that $94 \%$ demonstrated radiologic evidence of abnormality. CONCLUSION: The results demonstrated that the most prevalent symptoms and signs were fever, dyspnea and cough. Moreover, most patients were males and hospitalized. The rate of mortality and high level of CRP, ALT/AST and ALP is similar within the non-immune suppressed and general population. However, early detection of high level of serum CRP, ALT/AST and ALP combined with a clinical COVID-19 symptom and finding of CT scan may be used as an index for the presence and severity of the disease.

KEYWORDS: SARS-CoV-2, COVID-19, Liver transplantation, Systematic review

\section{INTRODUCTION}

In late December 2019, several very progressive pneumonia-like respiratory syndromes called COVID-19 (coronavirus 2019 disease), first occurred in Wuhan, Hubei Province, China (1-3). Severe acute respiratory syndrome coronavirus 2 (SARS-COV-2) is a zoonotic virus belonging to the Coronaviridae family, 
single-stranded, enveloped, non-segmented, positive-sense RNA genomes cause symptoms ranging from those similar to the common cold to interstitial pneumonia with acute respiratory distress syndrome (ARDS), with a case mortality percentage close to $8-10 \%(4-6)$. The primary transmission route of COVID-19 is through man-to-man via respirational droplets generated by breathing, sneezing, coughing from patients with pneumonia or asymptomatic patients, but the virus can also be transmitted through the fecal-oral route $(7,8)$. Since the beginning of the epidemic, it has increasingly been evidenced that older adults and patients with underlying diseases, including transplant recipients, have a greater risk for the development of lifethreatening and lethal respirational illnesses $(9,10)$. However, solid-organ transplant (SOT) receivers, like liver transplants, expectedly develop elevated levels of severe respiratory tract infections and fatality owing to the declined immunity caused by the use of immunosuppressive medications like steroids after organ transplantation $(11,12)$. There are currently limited data on the clinical course, the optimal therapeutic approach, and the outcomes of COVID-19 in the milieu of solid organ transplantation, particularly liver transplant receivers, and the evidence is limited to case reports and small case series $(1,13-15)$. In the European cohort of liver transplant patients infected with COVID-19, Becchetti et al. reported during hospital stay, mortality percentages were $12 \%$ and $17 \%$, respectively (16). Another study from Iran indicated that the use of the immunosuppressive drugs not only had no increasing effect on death rates, but also positively affected the reduction of the disease intensity and clinical duration (17).

Since limited information is available about the COVID-19 infection in liver transplant receivers, particularly information regarding the management of immunosuppressant's and fatality rates, this review aimed to conduct a comprehensive systematic review of the available data about clinical presentations, laboratory changes and outcomes of SARSCOV-2 in liver transplant recipients.

\section{METHODS}

Study design and search strategies: This present review conforms to the "Preferred Reporting Items for Systematic Reviews and Meta-Analyses" (PRISMA) statement. We carried out comprehensive systematic searches of the literature review of Web of Science, PubMed, Embase and Scopus. Search criteria included case reports and case series studies of relevant terms related to COVID-19 and SARS$\mathrm{CoV}-2$ in liver transplant patients published up to end of September, 2020 in languages other than English.

The search strategy for our review was based on the following keywords: "2019 novel coronavirus" OR "severe acute respiratory syndrome coronavirus 2" OR "SARS-CoV-2 infection" OR "2019- nCoV infection" OR "novel coronavirus" OR "coronavirus disease 2019" OR “COVID-19” AND "Liver" AND "transplant" OR "graft".

Study selection: All studies met the following inclusion criteria: prospective or retrospective descriptive case reports and case series of liver transplants patients infected with COVID-19 which confirmed and diagnosed according to the criteria recommended by WHO. In addition, articles had to include diagnostic methods, clinical symptoms, laboratory or radiological findings, and outcomes. Articles describing other tissue transplantation as well as guidelines, unavailable full texts, duplicate publications without peer review processes and lack of sufficient data were excluded.

In the first stage, two reviewers (PS, AS) independently screened the title and abstracts of all eligible studies. Second, the full text of those abstracts which met the inclusion criteria was considered and independently reviewed by the same authors and disagreements were resolved between review authors (PS, AS and HN).

Data extraction: Two authors (PS, HN) independently extracted the data from the eligible studies using a pre-defined data extraction sheet. The following data such as patient demographics (e.g., age, sex), radiological and laboratory data, comorbidities, history of the transplanted organ, COVID-19 clinical manifestations (Signs, Symptoms), RT- 
PCR tests and patients' outcome were extracted. In the case of inconsistencies, the researchers discussed and resolved between review authors to reach consensus (PS, AS).

Statistical analysis: The statistical analysis was carried out using SPSS version 16.0 (SPSS Inc). Continuous variables were assessed as mean \pm standard deviation, and categorical variables were reported as counts and percentages.
The initial search revealed 256 relevant articles. After initial screening of titles and abstracts, duplicate citations and irrelevant articles were excluded by title and abstract assessment. In the secondary evaluation, 25 studies were included and analyzed in this review (18-42). Figure 1 depicts the flow diagram of the details of the literature search based on the PRISMA statement, as well as the selection criteria for the articles.

\section{RESULTS}
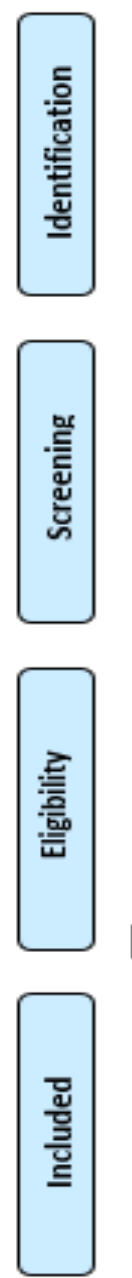
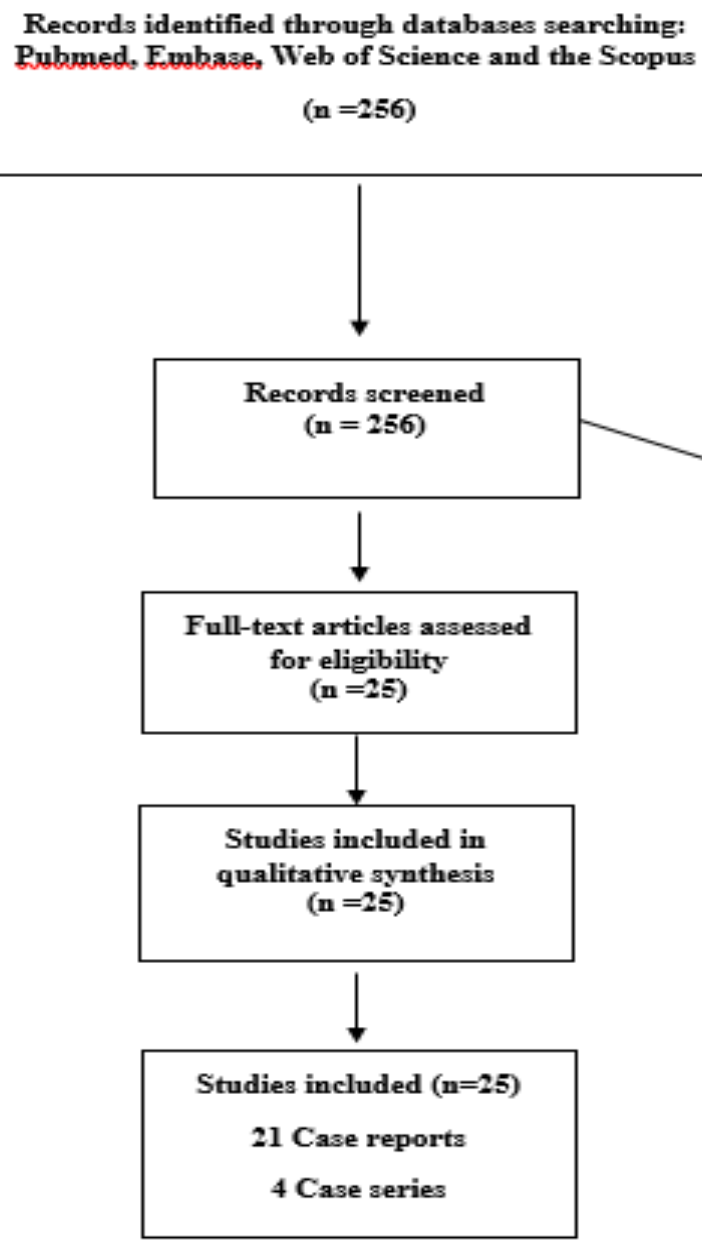

Records excluded after title and abstract screening $(\mathrm{n}=\mathbf{2 3 1})$

Figure 1: Flow chart of study selection for inclusion in the systematic review

Screening the inclusion criteria to the full-text articles, 21 case reports and 4 case series from 8 countries were recognized with 59 unique cases of COVID-19 (Table 1). Studies included reports from the United States, China, Italy, Iran, Spain, France, Brazil, and Denmark. 
Table 1: Characteristics of the included articles

\begin{tabular}{|c|c|c|c|c|c|c|c|c|c|}
\hline & Authors & Country & $\begin{array}{l}\text { Publish } \\
\text { ed time }\end{array}$ & Type of study & Age & $\begin{array}{c}\text { Male/ } \\
\text { Female }\end{array}$ & $\begin{array}{c}\text { No. of } \\
\text { patient (s) }\end{array}$ & Diagnostic methods & Outcome \\
\hline 1. & Bin et al & China & 2020 & Case report & 50 & $\mathrm{M}$ & 1 & RT-PCR/CT-scan & Recovered \\
\hline 2. & $\begin{array}{l}\text { Barros, Machado } \\
\text { et al }\end{array}$ & Brazil & 2020 & Case report & 69 & M & 1 & RT-PCR/CT-scan & Recovered \\
\hline 3. & Donato et al & Italy & 2020 & Case series & 63 & $6 \mathrm{M}, 2 \mathrm{~F}$ & 8 & RT-PCR/CT-scan & $\begin{array}{l}6 \text { Recovered, } \\
2 \text { Hospitalized }\end{array}$ \\
\hline 4. & Gao et al & China & 2020 & Case report & 48.6 & $3 \mathrm{M}$ & 3 & RT-PCR/CT-scan & $\begin{array}{c}\text { 1Expired, } \\
\text { 2Recovered }\end{array}$ \\
\hline 5. & Hammami et al & USA & 2020 & Case report & 63 & M & 1 & RT-PCR/CT-scan & Recovered \\
\hline 6. & Kates et al & USA & 2020 & Case report & 67 & M & 1 & RT-PCR & Recovered \\
\hline 7. & Zhong et al & China & 2020 & Case report & 37 & M & 1 & RT-PCR & Recovered \\
\hline 8. & Qin et al & China & 2020 & Case report & 37 & M & 1 & RT-PCR & Recovered \\
\hline 9. & Morand et al & France & 2020 & Case report & 55months & $1 \mathrm{~F}$ & 1 & RT-PCR & Recovered \\
\hline 10. & Huang et al & China & 2020 & Case report & 59 & M & 1 & RT-PCR/CT-scan & Expired \\
\hline 11. & Bhoori et al & Italy & 2020 & Case report & $>65 y$ & $3 \mathrm{M}$ & 3 & RT-PCR & Expired \\
\hline 12. & Ruiz et al. & Spain & 2020 & Case series & 68 & $3 \mathrm{M}, 3 \mathrm{~F}$ & 6 & RT-PCR/CT-scan & $\begin{array}{l}\text { 2Expired, } \\
\text { 4Recovered }\end{array}$ \\
\hline 13. & Nikoupour et al & Iran & 2020 & Case report & 35 & M & 1 & RT-PCR & Recovered \\
\hline 14. & Niknam et al & Iran & 2020 & Case series & 53 & $1 \mathrm{M}, 1 \mathrm{~F}$ & 2 & RT-PCR/CT-scan & Recovered \\
\hline 15. & Stephen et al & USA & 2020 & Case report & 6 months & $\mathrm{F}$ & 1 & RT-PCR & Recovered \\
\hline 16. & Heinz et al & USA & 2020 & Case report & 6 months & $\mathrm{F}$ & 1 & RT-PCR & Recovered \\
\hline 17. & Nikoupour et al & Iran & 2020 & Case report & 3 & M & 1 & RT-PCR & Expired \\
\hline 18. & Mathiasen et al & Denmark & 2020 & Case report & 58 & $\mathrm{~F}$ & 1 & RT-PCR & Recovered \\
\hline 19. & Maggi et al & Italy & 2020 & Case report & 65 & $2 \mathrm{M}$ & 2 & RT-PCR & $\begin{array}{l}1 \text { Expired, } \\
1 \text { Recovered }\end{array}$ \\
\hline 20. & Fung et al & USA & 2020 & Case report & 80 & F & 1 & RT-PCR & hospitalized \\
\hline 21. & Loinaz et al & Spain & 2020 & Case series & 62 & $5 \mathrm{~F}, 12 \mathrm{M}$ & 19 & RT-PCR & $\begin{array}{l}\text { 2Expired, } \\
\text { 15Recovered }\end{array}$ \\
\hline 22. & Modi et al & USA & 2020 & Case report & 32 & M & 1 & RT-PCR & Recovered \\
\hline 23. & Prieto et al & Spain & 2020 & Case report & 52 & M & 1 & RT-PCR & Recovered \\
\hline 24. & Antony et al & USA & 2020 & Case report & 63 & M & 1 & RT-PCR & Recovered \\
\hline 25. & Song et al & China & 2020 & Case report & 37 & M & 1 & RT-PCR & Recovered \\
\hline
\end{tabular}

DOI: http://dx.doi.org/10.4314/ejhs.v31i2.26 
Among the 59 patients included, 78.3\% were over 50 years old, and $71.6 \%$ were males. The patients' mean and age range were $50.8(6 \mathrm{~m}$ $80 \mathrm{y})$. The majority, $68.3 \%(41 / 60)$, of the patients experienced infection 2 years after transplantation, and only 10 patients were diagnosed during the first year of transplant $(19,20,26,27,30,34,37-43)$. The majority of the patients $(93.3 \%)$ were hospitalized during the course of illness.

The most common presenting symptoms were fever $(72.9 \%)$, dyspnea and cough $(54.2 \%)$, followed by myalgia/fatigue, sore throat, headache, diarrhea and chills (Table 2). Additionally, in studies describing C-reactive protein (CRP) values, the majority of the patients revealed a high level of CRP (64.3\%). Moreover, high-levels of ALT, AST and ALP were reported in $64.3,37.5,30.5$ and $22.2 \%$ of patients, respectively. We found 3/60 (13.2\%) reports on Acute Respiratory Distress Syndrome (ARDS). Mortality outcomes were reported in all of studies. Furthermore, $9(15.3 \%)$ of the cases died from complications of COVID-19. Among reported comorbidities such as pulmonary disease, diabetes, hypertension, hepatitis B cirrhosis and cardiovascular disease, hypertension was the most prevalent with $22 \%$ (13/59) frequency. Chest radiograph was reported in $72.9 \%(43 / 59)$ of the cases. Of these, 94\% demonstrated the radiologic evidence of abnormality. Chest CT scan was frequently reported with ground-glassopacity (GGO) patterns $(75 \%)$ as well as with bilateral lung involvement (75\%).

Table 2: Summary of the case report and case series findings

\begin{tabular}{|c|c|c|c|}
\hline & Variables & Number* & Percent \\
\hline \multirow{17}{*}{$\begin{array}{l}\text { Clinical } \\
\text { manifestations }\end{array}$} & Fever & $43 / 59$ & 72.9 \\
\hline & Cough & $32 / 59$ & 54.2 \\
\hline & Dyspnea & $32 / 59$ & 54.2 \\
\hline & Myalgia/fatigue & $12 / 59$ & 20.3 \\
\hline & Sore throat & $5 / 59$ & 8.5 \\
\hline & Headache & $5 / 59$ & 8.5 \\
\hline & Diarrhea & $8 / 59$ & 13.6 \\
\hline & Rhinorrhea & $0 / 59$ & 0 \\
\hline & Chills & $3 / 59$ & 5.1 \\
\hline & High CRP & $18 / 28$ & 64.3 \\
\hline & & & Range: $1-102 \mathrm{mg} / \mathrm{L}$ \\
\hline & High AST & $12 / 32$ & 37.5 \\
\hline & & & Range: $17-770 \mathrm{U} / \mathrm{L}$ \\
\hline & High ALT & $11 / 36$ & 30.5 \\
\hline & & & Range: 3-333 U/L \\
\hline & ALP & $6 / 27$ & 22.2 \\
\hline & & & Range: 41-1140 U/L \\
\hline \multirow[t]{4}{*}{$\mathrm{CT}$} & Both of GGO and Consolidation & $3 / 12$ & 25 \\
\hline & GGO without Consolidation & $9 / 12$ & 75 \\
\hline & Unilateral & $3 / 12$ & 25 \\
\hline & Bi lateral & $9 / 12$ & 75 \\
\hline \multirow[t]{2}{*}{ Complications } & ARDS & $3 / 59$ & 5.1 \\
\hline & Hospitalization & $56 / 59$ & 93.3 \\
\hline \multirow[t]{2}{*}{ Outcomes } & Discharged & $51 / 59$ & 85 \\
\hline & Death & $9 / 59$ & 15.3 \\
\hline
\end{tabular}

DOI: http://dx.doi.org/10.4314/ejhs.v31i1.26 


\section{DISCUSSION}

In this study, we assessed the clinical characteristics and epidemiologic features of case series and case report of liver transplant patients to gain a better understanding of the true risk of this complication caused by SARS CoV2 in liver transplant recipients. The previous literature review and case series affirm the notion that COVID-19 disease occurs more severely in the receivers of solid organ transplants and are further disposed to hospital stay with greater fatality percentages due to COVID-19 compared to the patients without transplants $(44,45)$. However, there are limited reviews on case reports about SOT patients $(6,44)$.

Here, we summarized the details and characteristics of 59 liver transplant recipients who developed COVID-19, including nine $(15.3 \%)$ who died from respiratory failure. This trial recorded almost two-thirds of male patients aged around 50.8 years on average. In a recently published meta-analysis, 337 transplantation patients were at the age of 49.9 years on average, and men comprised $70 \%$ of patients (10). Nevertheless, the greater percentage of COVID-19 in male transplant receivers could be because men comprised a greater percentage in transplant patients according to the literature (46).

Furthermore, the association between the SOT status and fatality was examined in a descriptive study. The results of this study indicate that the fatality rate among COVID-19 SOT receivers is the same as general population; however, higher rate of respiratory failure was observed in SOT recipients than in the general population (9).

Based on our results, it appears that the timeline of transplantation was not considered as an important role in the development of infection in these cases. Contrary to our results, Rinaldi et al. demonstrated that the timetable of transplantation apparently considerably contributed to the progress of infection, where they reported greater levels of acute respirational failure among patients who experienced transplantation during 1 year from COVID-19 detection compared to lately transplanted receivers (9). Their results suggest that the severity of immunosuppression apparently strongly correlates with the risk of developing a more acute disease.

According to our reviewed articles, hypertension, diabetes, and pulmonary disease were the most common co-morbidities among COVID-19 patients, which were associated with a more severe clinical course (47); this is also mentioned in our findings and is consistent with reports by Fraser et al. and Tahvildari et al. $(44,48)$. In this regard, Fraser et al., in one quantitative analysis on liver transplant recipients reported that ages over 60 years old and diabetes mellitus were significantly associated with fatality (44). Therefore, they recommended that liver transplant patients with common comorbidities would require close monitoring.

According to the review studies, the mostprevalent symptoms and signs were fever, dyspnea, cough, and myalgia/fatigue, while diarrhea, headache, sore throat and chills were less common clinical manifestations $(9,11,28,41,49)$. Although transplanted patients may represent with slight or unusual signs and with no fever, doctors must adopt wide differential diagnostic procedures and high suspicion clinically (43). Additionally, the present findings totally correspond to the same clinical profile of the general population with highly widespread indications such as fever, cough, and dyspnea. In line with our findings, a case series study of five transplant patients in China demonstrated that highly widespread indications on admittance were fever, cough, myalgia/fatigue, and sputum production (25).

According to previous reports, gastrointestinal indications were more frequent in liver transplant receivers with COVID-19 $(28.6 \%)$ than in the general population, being partially comparable to our reports among solid organ transplant cases (44). The most frequent abnormalities were high level of CRP, ALT/AST and ALP. These laboratory abnormalities may indicate the severity of disease and developing complications in LTP (50). The percentages of hepatitis were apparently greater inpatients with acute COVID19 exhibiting elevated liver enzyme than slight to medium illness (50). Interestingly, patients 
with high levels of ALT and ASTunderwent transplantation during two years from COVID19 detection.

Accordingly, Tahvildari et al., in one metaanalysis, reported that 60,48 and $28.5 \%$ of patients had high levels of CRP, ALT and AST, being partially in agreement with our results (48).

Moreover, in a meta-analysis that systematically reviewed 20 investigations with 3428 COVID-19 cases, elevated serum concentrations of AST, ALT, and total bilirubin were correlated with significantly increased intensity of COVID-19(51). One point to be considered is that close monitoring and management of immunosuppressant treatment in transplant patients affected by COVID-19 are essential. The standard and balanced treatment dosing allows sufficient immune reaction to repress viral loading and prevent transplant refusal (44).

However, antiviral treatment in isolation is not a sufficient therapy and supports the theory that ARDS is the result of the cytokine storm. In this regard, Zhong et al., in a liver-transplanted patient with COVID-19, notices that acute transplant rejection occurred despite retaining sufficient immunosuppression according to lymphocyte subtests. Among 51 patients with reports of radiological results, 94\% possessed radiographic or CT results "indicative" of being diagnosed with COVID-19 $(28,43)$.

In conclusion, we investigated and summarized the clinical characteristics, laboratory abnormalities, common comorbidities, and imaging modalities in the liver-transplanted population with COVID-19. The results demonstrated that the most prevalent symptoms and signs were fever, dyspnea, cough, and myalgia/fatigue. Moreover, most patients were males and hospitalized.

The rate of mortality and high level of CRP, ALT/AST and ALP is similar within the non-immune suppressed and general population. However, early detection of high level of serum CRP, ALT/AST and ALP combined with a clinical COVID-19 symptom and CT scan findings may be used as an index for the presence and severity of the disease.

\section{REFERENCES}

1. Mirzaie A, Halaji M, Dehkordi FS, Ranjbar $\mathrm{R}$, Noorbazargan $\mathrm{H}$ : A narrative literature review on traditional medicine options for treatment of corona virus disease 2019 (COVID-19). Complement Ther Clin Pract. 2020; 40:101214.

2. Mohammadpour S, Torshizi Esfahani A, Halaji M, Lak M, Ranjbar R: An updated review of the association of host genetic factors with susceptibility and resistance to COVID-19. J Cell Physiol. 2021; 236:49-54.

3. Halaji M, Farahani A, Ranjbar R, Heiat M, Dehkordi FS: Emerging coronaviruses: first SARS, second MERS and third SARS-CoV2: epidemiological updates of COVID-19. Infez Med. 2020; 28:6-17.

4. Hassan SA, Sheikh FN, Jamal S, Ezeh JK, Akhtar A: Coronavirus (COVID-19): A Review of Clinical Features, Diagnosis, and Treatment. Cureus. 2020; 12:e7355.

5. Carvalho A, Cezarotti Filho ML, Azevedo PCP, Silveira Filho RN, Barbosa FT, Rocha TJM et al: Epidemiology, diagnosis, treatment, and future perspectives concerning SARS-COV-2: a review article. Rev Assoc Med Bras (1992). 2020; 66:370374.

6. Nacif LS, Zanini LY, Waisberg DR, Pinheiro RS, Galvão F, Andraus W et al: COVID-19 in solid organ transplantation patients: A systematic review. Clinics (Sao Paulo, Brazil). 2020; 75:e1983.

7. Sheikhshahrokh A, Ranjbar R, Saeidi E, Dehkordi FS, Heiat M, Ghasemi-Dehkordi P et al: Frontier therapeutics and vaccine strategies for sars-cov-2 (COVID-19): A review. Iran J Public Health. 2020; 49:1829.

8. Karbasi A, Abyazi MA, Hashemi Aghdam M, Bahardoust M, Heiat F, Yaali Jahromi A et al: Evaluating the Effects of Common Health Instructions and Proceedings on COVID-19 Prevention. J Appl Biotechnol Rep. 2020;7:233-6.

9. Rinaldi M, Bartoletti M, Bussini L, Pancaldi L, Pascale R, Comai G et al: COVID-19 in solid organ transplant recipients: No 
difference in survival compared to general population. Transpl Infect Dis. 2020:e13421.

10. Moosavi SA, Mashhadiagha A, Motazedian $\mathrm{N}$, Hashemazar A, Hoveidaei AH, Bolignano D: COVID-19 clinical manifestations and treatment strategies among solid-organ recipients: a systematic review of cases. Transpl Infect Dis. 2020:e13427.

11. Molaei H, Khedmat L, Nemati E, Rostami $\mathrm{Z}$, Saadat $\mathrm{SH}$ : Iranian kidney transplant recipients with COVID-19 infection: Clinical outcomes and cytomegalovirus coinfection. Transpl Infect Dis. 2020:e13455.

12. Hasannejad-Bibalan M, Hekmatnezhad H: A light shining through darkness: probiotic against COVID-19. J Curr Biomed Rep. 2020; $1: 1-2$.

13. Kolonko A, Dudzicz S, Wiecek A, Król R: COVID-19 infection in solid organ transplant recipients: A single-center experience with patients immediately after transplantation. Transpl Infect Dis. 2020:e13381.

14. Dooghaie Moghadam A, Eslami P, RazaviKhorasani N, Moazzami B, Mousavizadeh M, Zali MR et al: The Impacts of the COVID-19 Pandemic on Liver Transplant Patients; Time to Change the Priorities. Arch Iran Med. 2020; 23:507-508.

15. Torabi R, Ranjbar R, Halaji M, Heiat M: Aptamers, the bivalent agents as probes and therapies for coronavirus infections: A systematic review. Mol Cell Probes. 2020; 53:101636.

16. Becchetti C, Zambelli MF, Pasulo L, Donato MF, Invernizzi F, Detry O et al: COVID-19 in an international European liver transplant recipient cohort. Gut. 2020; 69:1832-1840.

17. Sheikhalipour Z, Kakaei F, Khalili AF, Vahedi L: Management of COVID-19 in Liver Transplant Recipients with Immunosuppressant Therapy: Experiences of an Iranian Transplant Registry. 2020.

18. de Barros Machado DJ, Ianhez LE: COVID-19 pneumonia in kidney transplant recipients-where we are? Transpl Infect Dis. 2020:e13306.
19. Donato MF, Invernizzi F, Lampertico $\mathrm{P}$, Rossi G: Health Status of Patients Who Underwent Liver Transplantation During the Coronavirus Outbreak at a Large Center in Milan, Italy. Clin Gastroenterol Hepatol. 2020: 18(9):2131-2133.e1.

20. Gao F, Zheng KI, Gu JY, George J, Zheng MH: COVID-19 and Liver Transplantation: lessons learned from three reported cases. Transpl Infect Dis. 2020:e13335.

21. Hammami MB, Garibaldi B, Shah P, Liu G, Jain T, Chen PH et al: Clinical Course of COVID-19 in a Liver Transplant Recipient on Hemodialysis and Response to Tocilizumab Therapy: A Case Report. $A m J$ Transplant. 2020; 20:2254-2259.

22. Kates OS, Fisher CE, Stankiewicz-Karita HC, Shepherd AK, Church EC, Kapnadak $\mathrm{SG}$ et al: Earliest cases of coronavirus disease 2019 (COVID-19) identified in solid organ transplant recipients in the United States. Am J Transplant. 2020;20:18851890.

23. Liu B, Wang Y, Zhao Y, Shi H, Zeng F, Chen Z: Successful treatment of severe COVID-19 pneumonia in a liver transplant recipient. Am J Transplant. 2020; 20:18911895.

24. Bhoori S, Rossi RE, Citterio D, Mazzaferro $\mathrm{V}$ : COVID-19 in long-term liver transplant patients: preliminary experience from an Italian transplant centre in Lombardy. Lancet Gastroenterol Hepatol. 2020; 5:532533.

25. Huang JF, Zheng KI, George J, Gao HN, Wei RN, Yan HD et al: Fatal outcome in a liver transplant recipient with COVID-19. Am J Transplant. 2020; 20:1907-1910

26. Morand A, Roquelaure B, Colson P, Amrane S, Bosdure E, Raoult D et al: Child with liver transplant recovers from COVID19 infection. A case report. Arch Pediatr. 2020; 27(5):275-276.

27. Qin J, Wang H, Qin X, Zhang P, Zhu L, Cai $\mathrm{J}$ et al: Perioperative presentation of COVID-19 disease in a liver transplant recipient. Hepatology. 2020; 72(4):14911493.

28. Zhong Z, Zhang Q, Xia H, Wang A, Liang $\mathrm{W}$, Zhou $\mathrm{W}$ et al: Clinical characteristics 
and immunosuppressant management of coronavirus disease 2019 in solid organ transplant recipients. Am $J$ Transplant. 2020; 20(7):1916-1921.

29. Fernández-Ruiz M, Andrés A, Loinaz C, Delgado JF, López-Medrano F, San Juan R et al: COVID-19 in solid organ transplant recipients: a single-center case series from Spain. Am J Transplant. 2020; 20(7):18491858.

30. Niknam R, Malek-Hosseini SA, Hashemieh SS, Dehghani M: COVID-19 in Liver Transplant Patients: Report of 2 Cases and Review of the Literature. Int Med Case Rep. 2020; 13:317.

31. Nikoupour H, Arasteh $\mathrm{P}$, Gholami S, Nikeghbalian S: Liver transplantation and COVID-19: a case report and cross comparison between two identical twins with COVID-19. BMC Surg. 2020; 20:181.

32. Nikoupour H, Kazemi K, Arasteh $P$, Ghazimoghadam S, Eghlimi H, Dara N et al: Pediatric liver transplantation and COVID19: a case report. BMC Surg. 2020; 20:1-3.

33. Fung M, Chiu CY, DeVoe C, Doernberg SB, Schwartz BS, Langelier C et al: Clinical Outcomes and Serologic Response in Solid Organ Transplant Recipients with COVID-19: A Case Series from the United States. Am J Transplant. 2020; 20:32253233.

34. Heinz N, Griesemer A, Kinney J, Vittorio J, Lagana SM, Goldner D et al: A case of an Infant with SARS-CoV-2 hepatitis early after liver transplantation. Pediatr Transplant. 2020:e13778.

35. Mathiasen VD, Oversoe SK, Ott P, JensenFangel S, Leth S: Recovery of moderate COVID-19 in a liver transplant recipient on continued immunosuppression: a case report. In: Transplant Proc: 2020;52:27032706.

36. Modi AR, Koval CE, Taege AJ, Modaresi Esfeh J, Eghtesad B, Menon KN et al: Coronavirus Disease 2019 in an Orthotopic Liver Transplant Recipient Living with Human Immunodeficiency Virus. Transpl Infect Dis. 2020;22:e13351.
37. Antony SJ, Singh J, de Jesus M, Lance J: Early use of tocilizumab in respiratory failure associated with acute COVID-19 pneumonia in recipients with solid organ transplantation. IDCases. 2020; 21:e00888.

38. Prieto M, Gastaca M, Ruiz P, Ventoso A, Palomares I: A case of COVID-19 immediately after liver transplantation: Not only bad news. Ann Hepatobiliary Pancreat Surg. 2020; 24:314.

39. Song S, Ma Z, Chen T, Deng L, Zhang Y, Mo $P$ et al: Clinical characteristics of four cancer patients with SARS-CoV-2 infection in Wuhan, China. Infect Dis Poverty. 2020;2;9:82.

40. Lagana SM, De Michele S, Lee MJ, Emond JC, Griesemer AD, Tulin-Silver SA et al: COVID-19 Associated Hepatitis Complicating Recent Living Donor Liver Transplantation. Arch Pathol Lab Med. 2020. DOI: 10.5858/arpa.2020-0186-SA

41. Loinaz C, Marcacuzco A, Fernández-Ruiz M, Caso O, Cambra F, San Juan R et al: Varied clinical presentation and outcome of SARS-CoV-2 infection in liver transplant recipients: Initial experience at a single center in Madrid, Spain. Transpl Infect Dis. 2020:e13372.

42. Umberto M, Luciano DC, Daniel Y, Michele C, Enrico R, Giorgio R et al: The impact of the COVID-19 outbreak on liver transplantation programs in Northern Italy. Am J Transplant. 2020; 20:1840-1848

43. Zhong D, Liang SY: Approach to Transplant Infectious Diseases in the Emergency Department. Emerg Med Clin North Am. 2018; 36:811-822.

44. Fraser J, Mousley J, Testro A, Smibert OC, Koshy AN: Clinical Presentation, Treatment, and Mortality Rate in Liver Transplant Recipients With Coronavirus Disease 2019: A Systematic Review and Quantitative Analysis. Transplant Proc. 2020; 52:2676-2683.

45. Farshidpour M, Kim D, Junna S, Merchant $\mathrm{J}$ : A brief review of liver injury in patients with Corona Virus Disease-19 during the pandemic. Indian J Gastroenterol. 2020; 39:232-235. 
46. Sevarolli MDL, Loschi TM, Pereira E, Miyaura VTO, Baccan M, Pavão DN: Epidemiologic Profile of Transplant Patients Treated by the Physiotherapy. Transplant Proc. 2018; 50:831-834.

47. Sanyaolu A, Okorie C, Marinkovic A, Patidar R, Younis K, Desai $P$ et al: Comorbidity and its Impact on Patients with COVID-19. SN Compr Clin Med. 2020:1-8.

48. Tahvildari A, Arbabi M, Farsi Y, Jamshidi $\mathrm{P}$, Hasanzadeh S, Calcagno TM et al: Clinical Features, Diagnosis, and Treatment of COVID-19 in Hospitalized Patients: A Systematic Review of Case Reports and Case Series. Front Med. 2020; 7:231.
49. Ahmadi A, Hekmatnezhad H: The sound of getting rid of coronavirus by RNA interference technology: RNAi against COVID-19. J Curr Biomed Rep. 2020; 1(2), 45-47

50. Cai Q, Huang D, Yu H, Zhu Z, Xia Z, Su Y et al: COVID-19: Abnormal liver function tests. J Hepatol. 2020; 73:566-574.

51. Youssef M, M HH, Attia AS, R ME, Omar $M$, Zora $G$ et al: COVID-19 and liver dysfunction: A systematic review and metaanalysis of retrospective studies. $J \mathrm{Med}$ Virol. 2020; 92: 1825- 1833. 